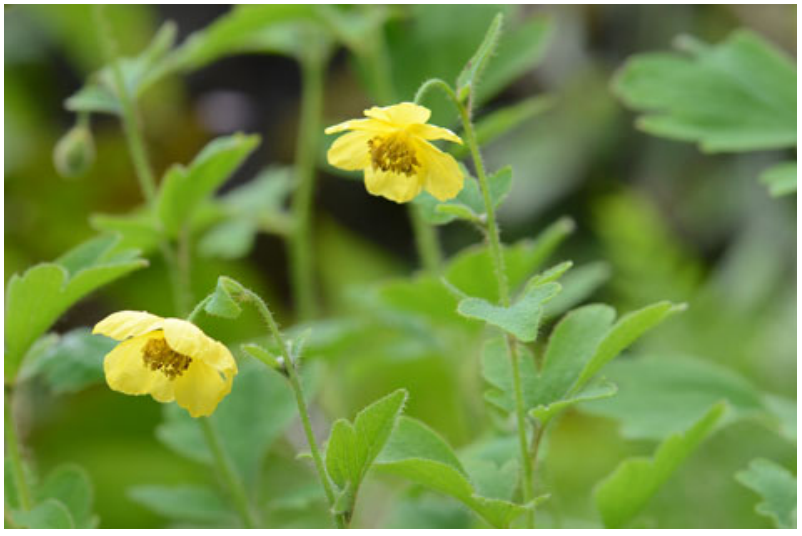

PLATE 1 Meconopsis smithiana. Photo: Rong Li.

occupancy of the species in these sites is c. $1,800 \mathrm{~m}^{2}$. This suggests that it should be categorized as Critically Endangered on the IUCN Red List on the basis of criterion B2ab(i,ii,iii,v). Also, because of its restricted distribution, small population size and the degradation of its habitat, the species should be included in the list of Plant Species with Extremely Small Populations in China (Sun et al., 2019, Trends in Plant Science, 24, 4-6). Our survey and information obtained from interviews with local people indicated that the main threats to this species are its small population size, the high frequency of destruction by grazing, and habitat loss as a result of road construction. Urgent and effective measures need to be taken to protect this species.

The Kunming Institute of Botany is now carrying out studies on the phylogeography of M. smithiana and its genetic relationships to other Meconopsis species of the southern Hengduan Mountains, to obtain a better understanding of the microevolution of this species. With the collaboration of the staff of nature reserves, we are planning to collect seeds of M. smithiana for ex situ propagation and potential future restoration of the species in the wild. Using species distribution models we also plan to identify and explore other sites in China where the species could potentially occur.

RONG LI (® orcid.org/0000-0003-0587-8130), MENGYU WANG, JUAN YUE and ZHIYOU WANG Key Laboratory for Plant Diversity and Biogeography of East Asia, Kunming Institute of Botany, Chinese Academy of Sciences, Kunming, China E-mail lirong@mail.kib.ac.cn

\section{Key skills for future aquatic scientists in Latin America: academic capacity building through the CORRIENTE XXI project}

Aquatic ecosystems harbour unique biodiversity and provide key ecosystem services. Conserving and sustainably managing marine and freshwater systems in times of global change requires specific skills that aquatic scientists need to acquire and develop throughout their career. Higher education institutions have a responsibility to provide relevant and up-to-date science-based education, especially at the postgraduate level. To identify the essential competences that MSc students should acquire, the insights of multiple stakeholders are needed.

During 20-24 January 2020 a workshop was dedicated to the identification of a portfolio of competences and learning outcomes for future aquatic scientists in Quito, Ecuador. The workshop was the first scientific meeting for the CORRIENTE XXI project, funded by the European Union, which aims to support innovative education for research-based and sustainable management of marine and freshwater ecosystems. This joint project focuses on curriculum development through international capacity building between Peru, Ecuador, France and Belgium. For this workshop, academics gathered to develop a shared, systematic approach to identify competences for postgraduates of existing and planned MSc programmes in aquatic sciences, and to assess the expectations of students, recent graduates, teachers and future employers.

The overall objective of the workshop was to share knowledge on portfolios of competences and learning outcomes through training. During the workshop, the six partner universities worked towards acquiring the necessary skills to design and analyse surveys and to establish a portfolio of competences, which will be the basis of updated and new MSc programmes. The workshop comprised stakeholder analysis by each higher education institution, development of customized surveys for the four stakeholder groups, preparation of data analysis and dissemination, and capacity building on survey methods.

These analyses have been distributed amongst the stakeholders. The findings will be a key input for the first CORRIENTE XXI meeting, in the second half of 2020, and will be the basis for curriculum update and development in the universities involved in Peru and Ecuador. Overall, the 3-year CORRIENTE XXI project addresses pressing environmental issues by providing research-based academic training, a framework for transboundary cooperation between higher education institutions for sciencebased solutions to shared challenges, and academic capacity building for teaching personnel. The project will result in two new MSc programmes in Ecuador and the update of three MSc programmes in both Ecuador and Peru. Activities (workshops, staff training, job-shadowing activities, an integrative conference, an innovative job fair, and a summer school) will train Peruvian and Ecuadorian academic staff in innovative and integrative skills. CORRIENTE XXI aims to raise the level of the MSc programmes, increase graduate employability, and raise awareness of the importance of aquatic sciences and management. This will translate into more effective guidelines 
for policy and management both nationally and in transboundary regions, and improved national and international scientific collaboration.

The findings of the stakeholder surveys will feed directly into the development of a portfolio of competences and learning outcomes for the MSc programmes in a region that depends heavily on the sustainable management of abundant yet declining natural resources, often shared between neighbouring countries. The focus of CORRIENTE XXI on sustainable development skills, on graduate employability and on research-based higher education is in line with the objectives of the upcoming United Nations Decade of Ocean Science for Sustainable Development. For more information about the project, please contact Jean Hugé.

Diana Di NitTo and Nico Koedam Vrije Universiteit Brussel, Brussels, Belgium

JEAN HUGÉ (๑ orcid.org/0000-0002-3695-547X) Vrije Universiteit Brussel, Brussels, Belgium, and Open University of the Netherlands, Heerlen, The Netherlands

E-mail jean.huge@ulb.ac.be

Francisco Benitez-Capistros, LuCy BaLdeon Rojas, XaVIer BoliVAR LASTRA BRAVO and Dario AleXander CePEDA-BAstidas Universidad Central del Ecuador, Quito, Ecuador

Isabel Timpe-Vera, GLadys Rincon-Polo, Jonathan Cedeno and RAFAel BERMUDEz Escuela Superior Politecnica del Litoral, Guayaquil, Ecuador

Ana Asuncion Huamantinco Araujo Universidad Nacional Mayor de San Marcos, Lima, Peru

\section{1st Sharjah International Conservation Forum for Arabia's Biodiversity}

The 21st Annual Sharjah International Conservation Forum for Arabia's Biodiversity was held at the Breeding Centre for Endangered Arabian Wildlife in Sharjah, United Arab Emirates, during 3-6 February 2020. This Forum brought together over 180 participants from Jordan, Kuwait, Yemen, Bahrain, UAE, Saudi Arabia and Oman, and also from the UK, Germany, Canada, Denmark, South Africa, Australia and New Zealand. The Sharjah workshops are hosted by the Environment and Protected Areas Authority of the Government of Sharjah, under the patronage of H.H. Sheikh Dr Sultan bin Mohammed al Qasimi, Member of the Supreme Council and Ruler of Sharjah.

This was the first time the Forum has had a specific marine focus, chosen for 2020 to acknowledge the diversity and importance of the region's seas and oceans for biodiversity, and to broaden the reach of the Forum's primary objective, which is to promote conservation of the region's diverse and unique biota. The inclusion of the marine theme was particularly important this year as it provided an opportunity for regional marine scientists to begin preparations for the United Nations Decade of Ocean Science for Sustainable Development (2021-2030). This UN Decade was proclaimed to support efforts to address declines in ocean health and to create a common framework to ensure science can assist in creating improved conditions for sustainable development of the Ocean (en.unesco.org/ocean-decade).

Keynote speakers covered a range of regional topics, including the current conservation challenges facing coastal and marine biodiversity, coral reef status and restoration, fish and fisheries, cetaceans and dugongs, seabirds, mangrove restoration, marine protected areas and the projected impacts of climate change. Taxon-focused working groups considered the threats to and the conservation management needs for coastal and marine plants, corals, fish, seabirds and marine mammals. Common threats identified by the working groups included coastal development, pollution (particularly oil and plastics), overfishing, bycatch and the impacts of destructive fishing gear, desalination and climate change. Parallel veterinary components considered the care and management of seabirds, marine mammals and turtles. The challenges identified for improvement of marine research and conservation included the needs for greater transboundary cooperation between range states, adequate legislation, enforcement of existing legislation and expansion of representative marine protected area networks.

Outputs from previous Forum meetings are available from sicfab.ae/publications.

PHILIP SEDDON (৫ orcid.org/0000-0001-9076-9566)

Department of Zoology, University of Otago, Dunedin, New Zealand.E-mail philip.seddon@otago.ac.nz

GERHARD STEENKAMP Department of Companion Animal Clinical Studies, Faculty of Veterinary Science, University of Pretoria, Onderstepoort, South Africa

DAVID MALLON Division of Biology and Conservation Ecology, Manchester Metropolitan University, Manchester, UK, and IUCN/Species Survival Commission

HELEN SENN Royal Zoological Society of Scotland, Edinburgh Zoo, Edinburgh, UK

SARAH MAY ACT Parks and Conservation, Canberra, Australia

KEVIN BUDD and JANE BUDD Environment \& Protected Areas Authority, Breeding Centre for Endangered Arabian Wildlife, Sharjah, United Arab Emirates 